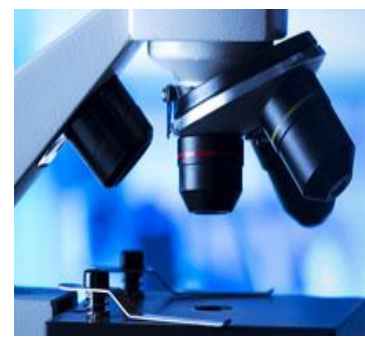

E-ISSN: 2707-4455

P-ISSN: 2707-4447

IJFM 2021; 3(1): 11-13

Received: 10-01-2021

Accepted: 12-03-2021

Dr. Lucky Yadav

Post Graduates, Department of Orthodontics and

Dentofacial Orthopaedics, Rajasthan Dental College and Hospital, Jaipur, Rajasthan, India

\section{Akanksha Jaswal}

Post Graduates, Department of Orthodontics and Dentofacial Orthopaedics, Rajasthan Dental College and Hospital, Jaipur, Rajasthan, India

\section{Renuka Bama}

Post Graduates, Department of Orthodontics and Dentofacial Orthopaedics, Rajasthan Dental College and Hospital, Jaipur, Rajasthan, India

\section{Ashish Kalawat}

Post Graduates, Department of Orthodontics and

Dentofacial Orthopaedics, Rajasthan Dental College and Hospital, Jaipur, Rajasthan, India

\section{Noopur Jha}

Post Graduates, Department of Orthodontics and Dentofacial Orthopaedics, Rajasthan Dental College and Hospital, Jaipur, Rajasthan, India

\section{Monika Khairwa}

Post Graduates, Department of Orthodontics and Dentofacial Orthopaedics, Rajasthan Dental College and Hospital, Jaipur, Rajasthan, India

\section{Corresponding Author:} Dr. Lucky Yadav

Post Graduates, Department of Orthodontics and Dentofacial Orthopaedics, Rajasthan Dental College and Hospital, Jaipur, Rajasthan, India

\section{Evaluation of the mesiodistal dimensions of the maxillary anterior teeth and its role in gender determination: An observational study}

\author{
Dr. Lucky Yadav, Akanksha Jaswal, Renuka Bamal, Ashish Kalawat, \\ Noopur Jha and Monika Khairwa
}

DOI: https://doi.org/10.33545/27074447.2021.v3.i1a.33

\begin{abstract}
Aim: To Study on Gender Determination Using Mesiodistal Dimensions of Anterior Teeth.

Methods: A prospective observational study was conducted in the Department of Orthodontics and Dentofacial Orthopaedics, Rajasthan Dental College and Hospital, Jaipur, Rajasthan, India for the period of one year. This study includes a total of 70 randomly selected study volunteers. The patients ranged in age from 20 to 30 years old, with no history or clinical signs of crown repair, orthodontic therapy, or trauma. Following informed permission, the mesiodistal dimensions of maxillary front teeth were measured between anatomical contact sites using a vernier calliper held parallel to the occlusal plane.

Results: The study's findings revealed that teeth 13 and 23 had sexual dimorphism, but teeth 11-22 had no statistically significant sexual dimorphism. When the degree of accuracy for sex determination was evaluated using 13 distinct males and females, it was discovered that 45 percent of females were accurately categorised and 55 percent of males were correctly classified. When the degree of accuracy for sex determination was evaluated using 23 distinct males and females, it was discovered that 62 percent of females and 62 percent of males were properly categorised.

Conclusion: The study found that maxillary canines had considerable sexual dimorphism and can be utilised for sex determination in conjunction with other techniques.
\end{abstract}

Keywords: anterior teeth, forensics odontology, mesiodistal dimension, sexual dimorphism

\section{Introduction}

One of the most significant factors in forensic identification is sex determination. Teeth, being the major component of the skull's masticatory system, are excellent sources of material for civil and medicolegal identification. When the rest of the body is injured beyond identification, teeth provide resilience to harm in terms of bacterial decomposition and fire, making them a vital asset in forensic inquiry ${ }^{[1]}$. Sexual dimorphism is defined as a systematic difference in form (either shape or size) between individuals of different sexes within the same species. Sexual dimorphism has been seen in the teeth of several animals ${ }^{[2]}$. In modern human communities, males have bigger dentitions than females.

The comparison of tooth measurements in males and females, or the frequency of nonmetric dental traits, such as Carabelli's trait of upper molars, is used to determine sex using dental features. The two most widely utilised and investigated characteristics in establishing sex based on dental measurements are the mesiodistal and buccolingual diameters of the permanent tooth crown ${ }^{[3]}$. Yuen et al. did a research on the mesiodistal dimension of deciduous and permanent teeth in the Southern Chinese population and discovered that there were no significant sex differences in size for any of the primary teeth or three of the permanent teeth. The percentage of sexual dimorphism in primary teeth ranged from 0.06 percent to 1.97 percent and 0.36 percent to 5.27 percent in permanent teeth ${ }^{[4]}$.

The most common method of obtaining data is through dental casts with a digital calliper. There are several measurements to consider, and their examination can be accomplished by direct comparison of measures, statistical analyses, or indexes. Only two prior researches used dental measures to develop possible predictive sex models for Portuguese people. Pereira et al. (2010) ${ }^{[5]}$ calculated incisors mesiodistal and canine diagonal distances using upper canine-to-canine teeth. 
The suggested approach lacks a comprehensive teeth analysis because it is limited to only six teeth. Silva et al. (2015) ${ }^{[6]}$, on the other hand, used the mandibular canine index 1 with a 64.2 percent success rate, concluding that this index should be restrictively applied to the Portuguese scenario in sex identification.

\section{Material and methods}

A prospective observational study was conducted in the Department of Orthodontics and Dentofacial Orthopaedics, Rajasthan Dental College and Hospital, Jaipur, Rajasthan, India for the period of one year, after taking the approval of the protocol review committee and institutional ethics committee. After taking informed consent detailed history was taken from the patient or the relatives. The technique, risks, benefits, results and associated complications of the procedure were discussed with all patients.

\section{Methodology}

This study includes a total of 70 randomly selected study volunteers. The patients ranged in age from 20 to 30 years old, with no history or clinical signs of crown repair, orthodontic therapy, or trauma. They had a full set of erupting teeth. The teeth were noncarious, nonattrited, intact, and peridontally healthy. All of the maxillary teeth were properly positioned. Following informed permission, the mesiodistal dimensions of maxillary front teeth were measured between anatomic contact sites using a vernier calliper held parallel to the occlusal plane. To minimise error, each reading was taken three times and the average of the three readings was calculated. The information gathered was subjected to statistical analysis.

\section{Results}

Statistical investigation revealed that only two of the six anterior permanent maxillary teeth were found to be statistically significant out of the six teeth selected. These teeth were numbered 13 and 23. The study's findings revealed that teeth 13 and 23 had sexual dimorphism, but teeth $11,12,21$, and 22 had no statistically significant sexual dimorphism.

\section{The precision of gender determination using 13 variables}

When the degree of accuracy for sex determination was evaluated using 13 distinct males and females, it was discovered that 45 percent of females were accurately categorised and 55 percent of males were correctly classified.

When the level of accuracy for sex determination was measured using 23 separately for males and females it was found that $62 \%$ females were classified correctly and $62 \%$ males were classified correctly.

The accuracy of determining gender using $13 \& 23$ When the level of accuracy for sex determination was measured using $13 \& 23$ together for males and females it was found that $65 \%$ females were classified correctly and $50 \%$ males were classified correctly.

\section{Percent dimorphism}

The percent to which the tooth size of males exceeded that of females was expressed as the male/female ratio minus.

In our study only tooth which showed significant percent dimorphism are $13 \& 23$.

Table 1: Tooth value male and female

\begin{tabular}{|c|c|c|c|c|c|}
\hline Tooth & Mean value male & Mean value female & SD male & SD female & P value \\
\hline 11 & 8.77 & 8.62 & 0.855 & 0.536 & 0.12 \\
\hline 12 & 6.87 & 6.85 & 0.663 & 0.645 & NA \\
\hline 13 & 7.86 & 7.54 & 0.636 & 0.652 & 0.05 \\
\hline 21 & 8.26 & 8.22 & 0.574 & 0.529 & 0.32 \\
\hline 22 & 6.87 & 6.76 & 0.687 & 0.689 & 0.69 \\
\hline 23 & 7.91 & 7.84 & 0.597 & 0.644 & 0.02 \\
\hline
\end{tabular}

\section{Discussion}

Gender identification in injured and disfigured deceased corpses or from skeletal remains is the first stage in medicolegal investigation and bioarchaeology. When it is feasible to anticipate the sex, identification becomes easier because only missing people of that sex must be considered ${ }^{[2]}$. Although the DNA profile produces precise findings, linear dimensions such as arthopometric or odontometric characteristics can be used to determine sex in a large population since they are simple, dependable, cheap, and quick to measure.

Given the variations in odontometric characteristics between populations, even within the same population, in the historical and evolutionary context, unique population values must be determined in order to allow identification based on dental measurements ${ }^{[3]}$. Thus, the study assessed the mesiodistal dimension of permanent maxillary incisors and canines in North Indian boys and girls.

Doris et al. found that early permanent dentitions give the greatest sample for tooth size assessments since early adulthood dentitions had less mutilation and attrition in most people. As a result, the impact of these variables on real mesiodistal tooth width would be minimal ${ }^{[7]}$. As a result, only participants aged 20 to 30 were included in the research sample.

Various odontometric measures, such as the mandibular canine index, 8 , buccolingual dimension of teeth, 3 , and tooth height, have been used to estimate sex ${ }^{[9]}$.

Sexual dimorphism refers to the systematic variations in form (size, shape, and colour) that exist between individuals of different sexes within the same species. Sexual dimorphism refers to gender variations in size, height, and appearance that can be used for dental identification. Keisu (1990) defines formalised. It is a valuable tool for differentiating them, particularly in forensic investigations. Teeth are very resilient, even when the rest of the body decomposes and is destroyed beyond recognition ${ }^{[8]}$.

Canines have been found from human remains in a variety of severe circumstances, including air catastrophes and storms. There are several explanations, but Moss believes it is related to men having thicker enamel due to a longer time of amelogenesis than females. Because of the $Y$ chromosome, male maturation is delayed ${ }^{[10,11]}$. According to the study done by Hashim HA and Murshid ZA in 1993, 
only canines demonstrated statistically significant sexual dimorphism in our investigation ${ }^{[12]}$.

\section{Conclusion}

The study found that maxillary canines had considerable sexual dimorphism and can be utilised for sex determination in conjunction with other techniques. Canines not only function as mouth cornerstones, but also as sex determination cornerstones in forensic examinations, especially when fragmented remains are found. Canines are important teeth for personal identity.

\section{References}

1. Rao NG, Rao NN, Pai ML, Kotian MS. Mandibular canine index - a clue for establishing sex identity. Forensic Sci Int 1989;42:249-54.

2. Dahberg AA. Dental traits as identification tools. Dent Prog 1963;3:155-60.

3. Iscan MY, Kedici PS. Sexual variation in bucco-lingual dimensions in Turkish dentition. Forensic Sci Int 2003; 137:160-4.

4. Yuen KK, So LL, Tang EL. Mesiodistal crown diameters of the primary and permanent teeth in Southern Chinese-a longitudinal study. Eur J Orthod. 1997;19:721-31

5. Pereira C, Bernardo M, Pestana D, Santos JC, De Mendonça MC. Contribution of teeth in human forensic identification-Discriminant function sexing odontometrical techniques in Portuguese population. J Forensic Leg. Med 2010;17:105-10.

6. Silva AM, Pereira ML, Gouveia S, Tavares JN, Azevedo Á, Caldas IM. A new approach to sex estimation using the mandibular canine index. Med. Sci. Law 2016;56:7-12

7. Doris JM, Bernard BW, Kuftinec MM, Stom D. A biometric study of tooth size and dental crowding. Am J Orthod 1981;79:326-36.

8. Kaushal S, Patnaik VV, Sood V, Agnihotri G. Sex determination in north Indians using mandibular canine index. JIAFM 2004;26:45-9.

9. Vodanović M, Demo Ž, Njemirovskij V, Keros J, Brkić H. Odontometrics: A useful method for sex determination in an archaeological skeletal population? J Archaeol Sci 2007;34:905-13.

10. Vito CD, Sauders SR. A Discriminant function analysis of deciduous teeth to determine sex. J Forensic Sci 1990:35:845-58.

11. Acharya BA, Mainali S. Univariate sex dimorphism in the Nepalese dentition and use of discriminant functions in gender assessment. Forensic Sci Int 2007:173:47-56.

12. Hashim MA, Murshid ZA. Mesiodistal tooth width: A comparision between saudi males and females, part1. Egypt Dent 1993;39;343-46. 